\title{
Development and Description of Conceptual Model Related to Employee Engagement in Organizations
}

\author{
Heena Atwal, Vikram Sandhu
}

\begin{abstract}
The humans are performing economic activities for their self-development by over-utilising the scarce and limited resources of nature. Moreover, the activities of humans damage the natural resources by polluting it. Engaged employees has the ability to make big differences if the organizations are able to provide positive psychological climate, resources for the job, management support as well as good working conditions. The present study took an initial step in using an empirically validated relationship model (with some modifications) to find relationship between employee willingness to promote eco-initiatives and dimensions of support for work environment. The proposed model has added some new dimensions to the conceptual categories of model, namely; organizational factors and biographical characteristics based on review of related literature which can prove to be useful in understanding the dimensions to engage the employees of the organizations in environmental protection and improvement.
\end{abstract}

Keywords : Sustainable Development, Employee Engagement, Eco-initiatives, Innovation, Environmental protection and improvement.

\section{INTRODUCTION}

The humans are performing economic activities for their self-development by over-utilising the scarce and limited resources of nature. Moreover, the activities of humans damage the natural resources by polluting it. At the same time, man is unable to replenish these natural resources by not taking care of their utilisation. The rapid increase in population of world is further escalating the environment problem. The developmental activities like construction of infrastructure, deforestation, industrial productions, nuclear explosions, etc. are responsible for environment pollution. Some other natural events are also source of pollution like earthquakes, volcanoes, tsunamis, forest fires etc. The important consequences of environment pollution include global warming, air pollution, destruction of earth's forests, loss of plants and diversity, and natural hazards like earthquakes, volcanoes, typhoons, landslides, droughts, floods and many more. Though the governments of many countries have made strict laws for the control of environment pollution but still to successfully implement these laws is individual's responsibility. This phenomenon is

Revised Manuscript Received on July 22, 2019

Dr. Heena Atwal , Assistant Professor, Department of Basic and Applied Sciences, Punjabi University, Patiala. Punjab. India

Dr.Vikram Sandhu, Assistant Professor, University Business School, Guru Nanak Dev University, Amritsar. Punjab. India

known as 'Environmentalism' which is urgently needed now. Environmental education has to be an essential component of individual's education so that they may have knowledge of environmental ethics. One should not be concerned of the fact that who is causing environmental pollution but everyone should strive to protect and conserve the environment. There is an important saying that 'Think Globally, but act Locally'. The development has emerged as leading cause for environment pollution. So, the present concern is that the nature of development should be sustainable. Sustainable Development means utilization of the natural resources in such a manner for development that the future generations too are able to enjoy those resources to their full extent. In this way, Sustainable Development also owes the moral obligation towards the future generations. It is a broader concept that includes not only environmental commitments but also political, social and economic commitments. So, in present times it consists of four main components, namely; natural capital; human capital; social capital; and reproducible capital. Natural Capital consists of biodiversity and various other natural assets; Reproducible Capital consists of durable structures or equipment that are made by the human beings; Human Capital consists of the productive potential of humans and their skills, ability, education etc; Social Capital consists of the institutions, rules, regulations and other agencies that has the capability of influencing the interactions with the humans (Sandhu, 2016).

The organizational activities are performed by the persons. So, the role of employees becomes very important and crucial for the organizations in the protection and improvement of the environment. It gives rise to the fact that if the organization has to work for the environment, its employees should have knowledge and education about the environmental concerns. This leads to the important role of employee engagement in the activities targeted for the protection and improvement of environment. The employee engagement has to be encouraged by the organization to devise means and measures for the protection of environment. This leads to the assumptions that organizational transitions towards environmental sustainability can be enhanced by organizations to create and implement environmental solutions (Ramus, 2000). These assumptions are drawn on four research streams. First, ecological sustainability of business depends upon 
innovative solutions. It means that sustainable business practices are dependent on efficient resources used in manufacturing and delivery of products and services. Second, the innovation is the resultant of creative ideas from the individuals and groups. Third, the literature highlights that the change process can be made by engaging employees. Fourth, for change to occur in organizations, organizational support for action of employees in determining the success of environmental efforts is important. This leads to the requirement for testing the effect of organizational factors and supervisory behaviour on the motivation of employees for generating new ideas for contributing in the area of environment management. In the lack of supportive management behaviour and/or the organizational communications, sustainable activities will lead to less environmental initiatives from employees.

'Employee Engagement' is considered to be a new term in human resource literature and this term came into prominence after the year 2000. Now, this term is widely used by the human resource practitioners and researchers. This term has been coined by the Gallup research group working in America. The term 'Employee Engagement' has gained importance as it has shown a statistical significant relationship with major human resource terms such as productivity, profitability, employee retention, safety, employee satisfaction as well as customer satisfaction (Buckingham and Coffman 1999, Coffman and Gonzalez-Molina 2002). Kahn (1990) defines engagement as an attachment of employees of the organization to their work and roles with respect to their jobs. It is the level of commitment and involvement of an employee towards his job and its values. It is degree of an employee's emotional attachment (positive or negative) to their job, peers and organizations. It indicates their willingness to learn and perform at the workplace. Employee engagement refers to the positive feeling that the employees develop towards their jobs and act as source of motivation for enhanced efforts made by them. It is condition of employee when he feels involved committed, passionate and empowered. It also influences the demonstrations of their feeling in their work behaviour.

The researchers have highlighted that engaged employees are in a position to contribute 100 per cent physically and psychologically to their work. The absence of engagement in the employees results into 'engagement gap' which is detrimental for the productivity and growth of the organizations (Kowalski, 2003).

The employee may be motivated and committed to their job without being necessarily engaged with overall strategies and objectives of the firm or without releasing broader impact of their efforts. Employee engagement is a combination of commitment of the employee to the organization and its values plus the willingness of the employee to help their colleagues. Likewise, Schmidt (2004) defines engagement as combination of satisfaction and commitment of the employees. Satisfaction indicates emotional or attitudinal element of the employees while commitment indicates motivational and physical elements of

the employees. So, according to Schmidt (2004) satisfaction and commitment are the two important elements of engagement but neither of these two elements is sufficient enough to guarantee engagement. Further, the employee engagement results into the participation and contribution of the employees in the overall performance of the organization. It also results in the development of pride among the employees with respect to their place of work as compared with people outside their organizations. Employee engagement makes the employee to 'go the extra miles' for the benefit of the organization. Engaged employees are readily and happily involved and perform their work with full devotion and concentration (Bakker et al., 2011). Engaged employees has the ability to make big differences if the organizations are able to provide positive psychological climate, resources for the job, management support as well as good working conditions.

Importance of Employee Engagement

Employee engagement has emerged as an important and critical element for the success of business (Slatten and Mehmetoglu, 2011). The following points highlight the importance of employee engagement:

1. Employee engagement has pleasurable experience for the employees who contribute to pro-activity; ability to adapt to work place changes and innovation at work place. It also helps the employees to face difficulties and adjusting to organizational changes.

2. Engaged employees work harder and contributes more to their job.

3. Engaged employee experiences greater pressure for their work and helps the organization to produce better quality products.

4. Employee engagement is the active psychological state of employees. They act to display extra-role behaviour than the other employees.

5. Engaging employees in environmental behaviour has emerged as an important topic in today's global economy.

The Massachusetts Institute of Technology Salon Management Review and Boston Consulting Group conducted a study on business sustainability which revealed that 56 per cent of corporate executives and managers selected "employee interest in sustainability" as an important issue that have a significant effect on the organization (Berns, 2009).

The study also found that the organizational policies and practices which promote employee engagement in environmental behaviour can be used to increase employee recruitment and retention (Bern, et al., 2009).

\section{OBJECTIVE OF THE STUDY}

1. To develop a conceptual model for determining the dimensions of employee engagement for the protection and improvement of environment.

2. To study the dimensions related to the employee eco-initiatives 


\section{REVIEW OF RELATED LITERATURE}

The problem of environment degradation is not a recent phenomenon; rather it has aroused from the centuries due to the negligence of the humans towards environment. The human activities have remained self-oriented without considering the environment as a whole. These activities have resulted into un-replenished harm to the environment and its components. The society has realized very late, to protect the environment. However, considerable attempts are made to protect and improve environment for sustainable development from the last 30 years. The review of literature will help us to identify the important issues involved in the areas of environment and to develop conceptual model on the basis of which objectives for the present study will be identified.

White, M.A. (1995) in his research study provided an environmentally responsible perspective for the development process by reviewing several major ways by which the organizations should respond to the environmental threat and opportunities. The author analyzed three important branches of finance namely; corporate finance; investments and financial institutions.

Delmas, M. A. (2000) in her research study revealed the competitive advantage achieved by the organizations by adopting ISO 14001standards. The author highlighted that the results of adoption of standards were not tangible but there were many underlying benefits of ISO 14001 standards. Hertin, J. and Berkhout, F. (2003) in his research study highlighted the importance of integration of environmental concerns with all other areas of formulation of organizational policies by developing a framework called as Environmental Policy Integration (EPI). This framework was used for the analysis and evaluation of organizational strategies for integrating them with environmental policy of the firm. Delmas, $\mathbf{M}$. and Toffel, M. (2005) in their research study examined the ways to explain significantly strategies of the organizations with the help of institutional theory. The authors found that the difference in distribution of power among the various internal departments of the organization resulted into the adoption of different pressures for implementing management practices. Simpson, M.R. (2009) in his research study concluded that organizational factors as well as individual factors had significant impact on employee engagement at work. Pati, S. P. and Kumar, P. (2010) in their study discussed that engaged employees were considered as strategic asset for organizations. The authors argued through theoretical arguments and empirical support that self-efficacy levels in employees were primarily responsible for the differences that occur in displaying engagement. Based on findings, the author defined engagement as expressed empowerment pertaining to a role. Brammer, S. et al. (2012) in their research study examined the role of Small and Medium Enterprises (SMEs) in adoption of wide range of environmental management practices for the protection of environment. The study found significant differences among small and medium enterprises for implementing environment management practices. Delmas, M. A., and Pekovic, S. (2013) in their research study examined the relationship between environmental standards with labour productivity and other mechanisms through which they interacted. Their study concluded that the firm adopting environmental standards increased their labour productivity. Chen, Y. et al. (2015) in their study found that market orientation of the firm effects environmental strategy of the firm in positive manner. This influenced on both environmental product quality and employees environmental involvement. The study also found that these two variables positively influenced environmental Sandhu, V. and Sidhu, A.S. (2015) in their research study analyzed some of the important provisions of World Trade Organization (WTO) agreements related to the protection and improvement of environment.

\section{DEVELOPMENT AND DESCRIPTION OF CONCEPTUAL MODEL}

The present section deals with the development and description of conceptual model that provides basis for developing survey instrument used in the study. The present study has modified the conceptual model made by the early studies 'Encouraging Innovative Environmental Actions: What Companies and Mangers must do' conducted by C. A. Ramus (2002) and 'The Role of Supervisory Support Behaviors and Environmental Policy in Employee "Eco initiatives" at Leading-Edge European Companies' conducted by C. A. Ramus and U. Steger (2000). The model has been used and tested by the researchers in 12 countries namely Austria, Belgium, Canada, Finland, France, Germany, Italy, Netherlands, Norway, Spain, UK and United States by taking employees of 6 industries as sampling unit of their study but no empirical study has been conducted in Punjab (India) to examine the nature and extent of the employee engagement for environmental creativity and innovation. So, the present study took an initial step in using an empirically validated relationship model (with some modifications) to find relationship between employee willingness to promote eco-initiatives and dimensions of support for work environment. Our model has added some new dimensions to the conceptual categories of model, namely; organizational factors and biographical characteristics based on review of related literature. The other two conceptual categories, namely; signal of organizational encouragement and signal of supervisory' encouragement were earlier existing in the model. The organizational factors include some of the specific characteristics of the organizations like category of organization (large/medium), total number of employees working in the organization, number of full-time employees working in the organization for the protection and improvement of environment, status of their certification (ISO 9000 and ISO 14001) etc (Brammer, S. et al., 2012). Similarly, bio-graphical characteristics of the employees include their age, gender, marital 
status, educational qualifications, working level in organization and length of service in present organization etc.

The signal of organizational encouragement is in the form of organization vision related to protection and improvement of environment highlighted in the form of Corporate Environment Policies (CEP). The Corporate Environment Policies (CEP) consist 13 environmental policies. The range of these policies was from 'having a written environmental policy' to 'adopting same environmental standards at home and abroad'. The supervisory encouragement is classified into 6 categories, namely; innovation; competence building; communication; information dissemination; rewards/recognitions; and management of goals and responsibilities in case of two types of supervisory behaviors related to environmental management and general management that existed in the managers of environmentally pro-active organizations.

It is perceived that all these independent variables have positive relationship with the dependent variable (employee eco-initiatives) leading to improved environmental performance of the organizations which is considered to be the overall goal of the environmentally pro-active organizations. The model guides the researcher to develop specific objectives as well as research questions of the study which will be discussed in the subsequent chapters.

\section{RESULTS}

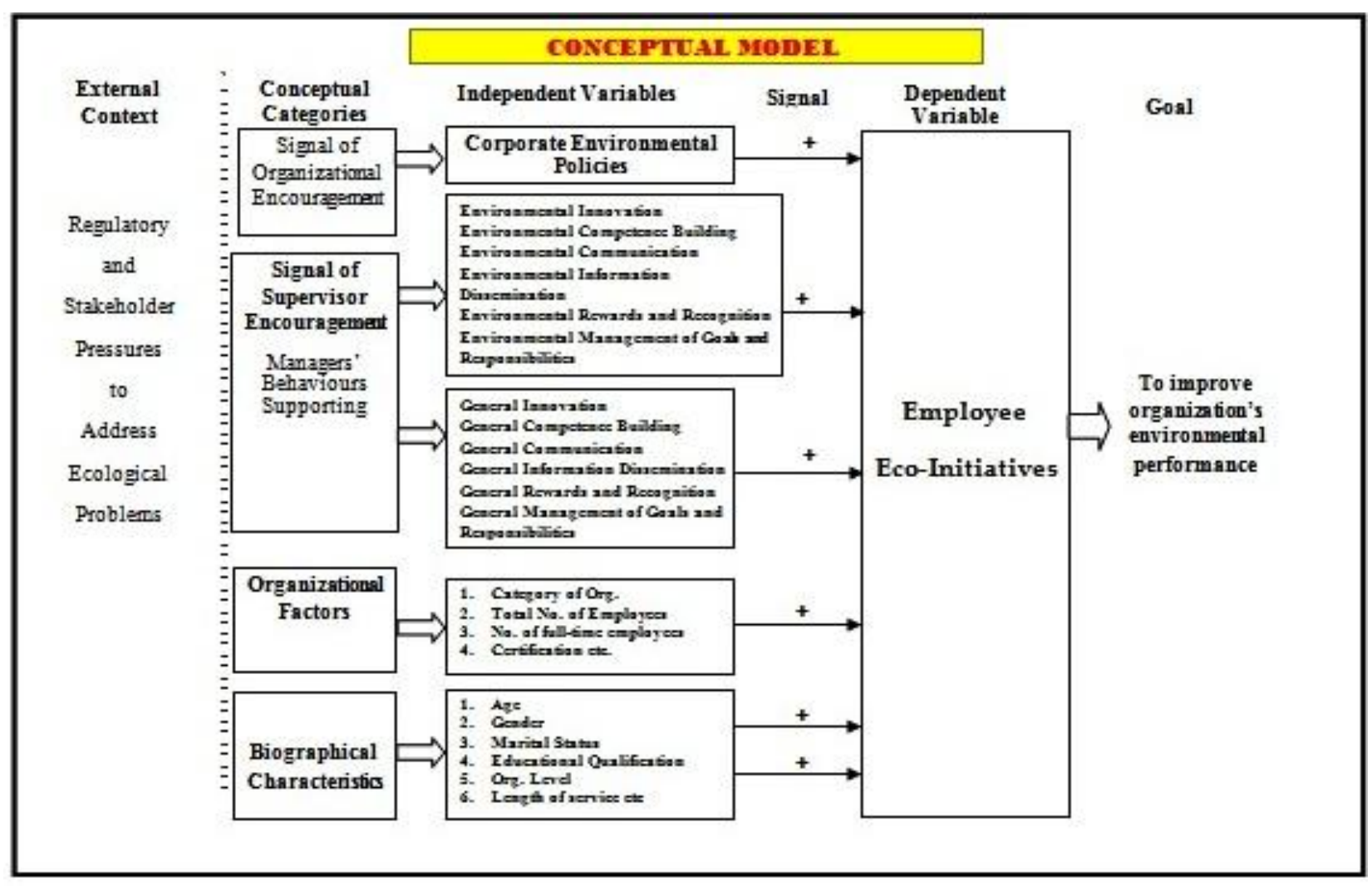

\section{CONCLUSION}

The people are performing financial exercises for their self-advancement by over-using the rare and constrained assets of nature. Also, the exercises of people harm the normal assets by contaminating it. Drawn in representatives can make huge contrasts if the associations can give positive mental atmosphere, assets for the activity, the board support just as great working conditions. The present investigation made an underlying stride in utilizing an exactly approved relationship model (with certain adjustments) to discover connection between representative eagerness to advance eco-activities and measurements of help for workplace. The proposed model has added some new measurements to the reasonable classifications of model, in particular; hierarchical variables and true to life attributes dependent on audit of related writing which can demonstrate to be valuable in understanding the measurements to connect with the workers of the associations in ecological security and improvement.

\section{REFERENCES}

1. Bakker, A. B., Albrecht, S. L., \& Leiter, M. P. (2011). Key question regarding work engagement. European Journal of Work and Organizational Psychology, 20(1), 4-28.

2. Brammer, S., Hoejmose, S., \& Marchant, K. (2012). Environmental Management in SMEs in the UK: Practices, Pressures and Perceived Benefits: Environmental Management in 
SMEs. Business Strategy and the Environment, 21(7). 423-434.

3. Buckingham, M. A. R. C. U. S., \& Coffman, C. (1999). Break All the Rules. London: Simon \& Shuster.

4. Chen, C. M., \& Delmas, M. (2011). Measuring Corporate Social Performance: An Efficiency Perspective: Measuring Corporate Social Performance with DEA. Production and Operations Management, 20(6), 789-804.

5. Coffman, C., \& Gonzalez-Molina, G. (2002). A new model: Great organizations win business by engaging the complex emotions of employees and customers. The Gallup Management Journal, 12-21.

6. Delmas, M. A. (2000). Barriers and Incentives to the Adoption of ISO 14001 by Firms in the United States. Duke Environmental, Law and Policy Forum, 11, 1.

7. Delmas, M. A., \& Pekovic, S. (2013). Environmental standards and labor productivity: Understanding the mechanisms that sustain sustainability: environmental standards and labor productivity. Journal of Organizational Behavior, 34(2), 230-252.

8. Delmas, M. A., \& Toffel, M. W. (2005). Institutional pressures and environmental strategies. Retrieved from website: http://escholarship.org/uc/item/ 1bw326ts.pdf

9. Hertin, J., \& Berkhout, F. (2003). Analysing Institutional Strategies for Environmental Policy Integration: The Case of EU Enterprise Policy. Journal of Environmental Policy \& Planning, 5(1), 39-56.

10. Hopkins, M. S., Townend, A., Khayat, Z., Balagopal, B., Reeves, M., \& Berns, M. (2009). The business of sustainability: what it means to managers now. MIT Sloan Management Review, 51(1), 20.

11. Kahn, W. A. (1990). Psychological Conditions of Personal Engagement and Disengagement at Work. Academy of Management Journal, 43:692-724.

12. Kowalski, B. (2003). The engagement gap. Training, 40 (4), 62.

13. Pati, S., \& Kumar, P. (2010). Employee Engagement: Role of Self-efficacy, Organizational Support \& Supervisor Support. Indian Journal of Industrial Relations, 46(1), 126-137.

14. Ramus, C. A., \& Steger, U. (2000). The Roles of Supervisory Support Behaviors and Environmental Policy in Employee "Ecoinitiatives" at Leading-Edge European Companies. Academy of Management journal, 43(4), 605-626

15. Sandhu, V. \& Sidhu, A. S. (2015). Environmental Governance in India: A Systematic Review of the Initiatives. Pacific Business Review International, 8(4), 49-57.

16. Sandhu, V. \& Sidhu, A. S. (2015). Environmental Protection and WTO Issues and Implications. EPRA International Journal of Economic and Business Reveiw, 3(10), 79-88.

17. Schmidt, F. (2004). Workplace well-being in the public sector-a review of the literature and the road ahead for the Public Service Human Resources Management Agency of Canada. Ottawa: PSRHMA.

18. Simpson, M. R. (2009). Engagement at work: A review of the literature. International Journal of Nursing Studies, 46(7), 1012-1024.

19. Slatten, T., \& Mehmetoglu, M. (2011). Antecedents and effects of engaged frontline employees: A study from the hospitality industry. Managing Service Quality: An International Journal, 21(1), 88-107.

20. White, M.A. (1995). Environmental Finance: Raising and using Funds in an Age of Ecology (paper presented at 4th International Conference of the Greening of Industry Network, Toronto, Canada). 